\title{
Product Design Innovation Based on the Theory of Value Engineering
}

\author{
Haoxin Wang \\ School of Art and Design \\ Huanghe Science and Technology College \\ Zhengzhou, China 450046
}

\begin{abstract}
Objective: the study is to establish the innovation value idea, improve the design innovation ability, promote upgrade of the industry, lower the product consumption, reduce the environmental pollution and promote leap of innovative products toward the middle and high end of the value chain. Method: for the product innovation, this paper puts forward application of the theory of value engineering and the comprehensive research methods such as system analysis, system induction, system evaluation, theoretical modeling. Conclusion: this paper comes to the conclusions that the product design innovation is the overall innovation of value, function and cost evaluation throughout the whole life of products; through innovation, we can optimize the function of products, reduce the cost, realize the maximum social value and obtain the reliable criterion of the value innovation.
\end{abstract}

Keywords-product design; value engineering; innovation; maximum value

\section{INTRODUCTION}

At present, the value judgment of the domestic industrial products derives from the profit-oriented market judgment of enterprises, which lays emphasis on the user value and the market value of products on the basis of the profit value of enterprises. However, it fails to count the negative value of products to environment, energy consumption, survival and health to the value judgment system and causes the market competition and evaluation on enterprise benefit under the one-sided value judgment. As a result, it forms the "market, benefit \& GDP emphasized and ecology, environment \& consumption neglected" development situation and leads to such social realistic harms as surplus of backward production capacity, serious environmental pollution and declination of the level of health of people. The design and manufacturing of the domestic industrial products is still in the low and middle end of the global industrial chain, is lack of system innovation ability and has low product value. The 18th National Congress of the Communist Party of China put forward the innovationdriven development strategy that scientific and technological innovation and design innovation powerfully promote the leap of the industry toward the middle and high end of the value chain, improve the overall quality of the economy, effectively overcome the resource and environment restrictions and enhance the sustainability of the development [1]. Aimed at realization of the maximum social value in the theory of value engineering, this paper analyzes the innovation of the industrial product design.

\section{OVERVIEW OF THE VALUE ENGINEERING}

The value engineering refers to thinking method and management technique which make system analysis to function and cost of the object of study through cooperation of all related fields so as to improve the value of the object of study [2]. The value engineering is a mature and effective management technique that can lower the cost and improve the value. The value in the value engineering is put forward as a level, namely, it is a level to evaluate the effectiveness of things. The value refers to the relation between cost and function, which can be expressed in the mathematical expression $\mathrm{V}=\mathrm{F} / \mathrm{C}$ where: $\mathrm{V}$-Value; F-Function (refers to the function of the whole life cycle); C-Cost (refers to the cost of the whole life cycle). This mathematical expression provides scientific standard for evaluation on the product value and also provides basis for measurement of appropriateness of function and cost and realization of necessary functions with the lowest cost [3]. With the progress of science and technology and development of cognition, concept and economic society, the theoretical connotation of the value engineering develops and innovates constantly.

\section{VALUE ENGINEERING ANALYSIS OF THE PRODUCT DESIGN INNOVATION}

In a long historic stage, people have thought that the product design pays close attention to the appearance design of products, which is an incomplete concept. The concept of the product design refers to the whole process design of products rather than appearance design of products. The innovation process of the industrial product design is multiple-level and multi-factor complex process with integrity, purpose and openness. From the respective of the value engineering, the product design innovation pays close attention to the relation between function and cost in the whole life process of products, namely, demand-strategy-plan-design-product-market-usediscard. The innovation pays close attention to not only enterprises and benefit but also users and the society. The attention to the function includes using function of consumers, profiting function of enterprises and the environmental utilitarian function (the environment utility refers to pollution reduction function, energy consumption reduction function and 
material consumption reduction function of the product innovation); the attention to the cost refers to the cost of the whole process, including research and development costs, manufacturing costs, marketing cost, environmental costs, use cost, discard cost and other costs, the goal of which is to realize the maximum social value of products through innovation [4]. The maximum social value refers to the maximum comprehensive social value of the value of users, the economic benefits of enterprises and the environmental utilitarian value in the whole life cycle of products rather than the maximum enterprise benefits.

\section{MAXimization OF THE SOCIAL VALUE OF ProduCT DESIGN INNOVATION}

Maximization of the social value of the product design innovation means that social resources can be rationally and fully used through innovation design of products so that interests of users, enterprises and the society can be maximally realized and the maximum economic and social benefits can be gained with the minimum resource consumption and the lowest environmental pollution [5]. The key of innovation in the meaning of the maximization of the social value is "evaluation on the basis of reliable criterion".

\section{A. Innovation and Function}

The function innovation is the central link of the product design innovation[6]. From the perspective of the maximization of the social value, the function includes using function of consumers, profiting function of enterprises and the utilitarian function of the environment. Measurement of the effectiveness of the innovation is required to analyze the acquisition of the above said three functions. However, these three functions have contradiction in the innovation practice of products. The method of solving the contradiction and realizing the effective innovation is the system innovation of products (as shown in the "Fig. 1", the legend of which is made by the author). The essence of the innovation is to make structure innovation, integrated innovation and collaborative innovation in environment, resources, materials, network, technology, art, management and market and other factors of product around the value goal of products. The structure innovation can be realized through function structure innovation, resource structure innovation and process structure innovation (as shown in the "Fig. 2", the legend of which is made by the author). Innovate the vertical hierarchy of function factor, resource factor and process factor of products and change the hierarchical setting, interhierarchical relation and hierarchical sequence[7]; innovate the function system, resource function, process function as well as horizontal structure among systems[8]; the innovation can be realized by changing quantity, quality and sequence of factors. For example, smart wearing device designed by the Apple Inc. in recent years is the typical case of the structure innovation of products. Through system integration, a large amount of knowledge of different fields is integrated to a relatively stable product [9]. The innovation can be realized through integration between function and function, integration between technology and technology, integration between technology and art and integration between original innovation and system integration. For example, Google Driverless Car researched and developed by the Google $\mathrm{X}$ laboratory is the typical achievement of integrated innovation. With the development of innovation, the product design becomes increasingly complicated. The product innovation often requires collaboration among several departments-innovation collaboration among scientific research department (professional institutions, colleges and universities and so on), relevant government departments, technical design department, factory departments and innovation collaboration among users, enterprises and the society. Only in this way can innovation resources be much more easily gained. When the shared innovation knowledge forms, the innovation efficiency will become higher; innovation achievements are easier to be transformed; innovation benefits will become broader; innovation risk will become lower [10]. For example, design innovation of electronic products on the premise of shared software and hardware resources, information resources, network resource based on the cloud computing technology of the internet makes such terminal products as television, computer and mobile phone simple, low consumption, super function and virtualized revolutionary changes and proves the achievement of collaborative innovation.

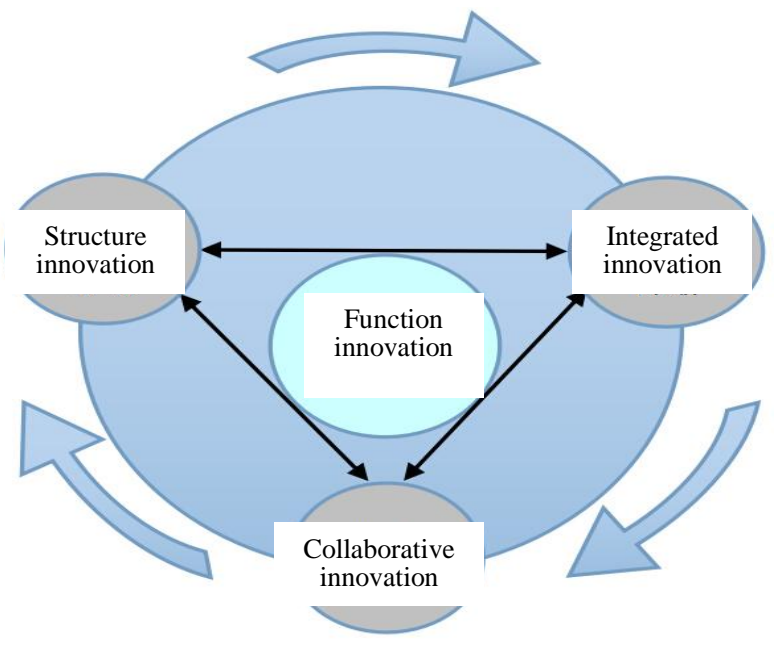

Fig. 1. Product Functional System Innovation Model. 


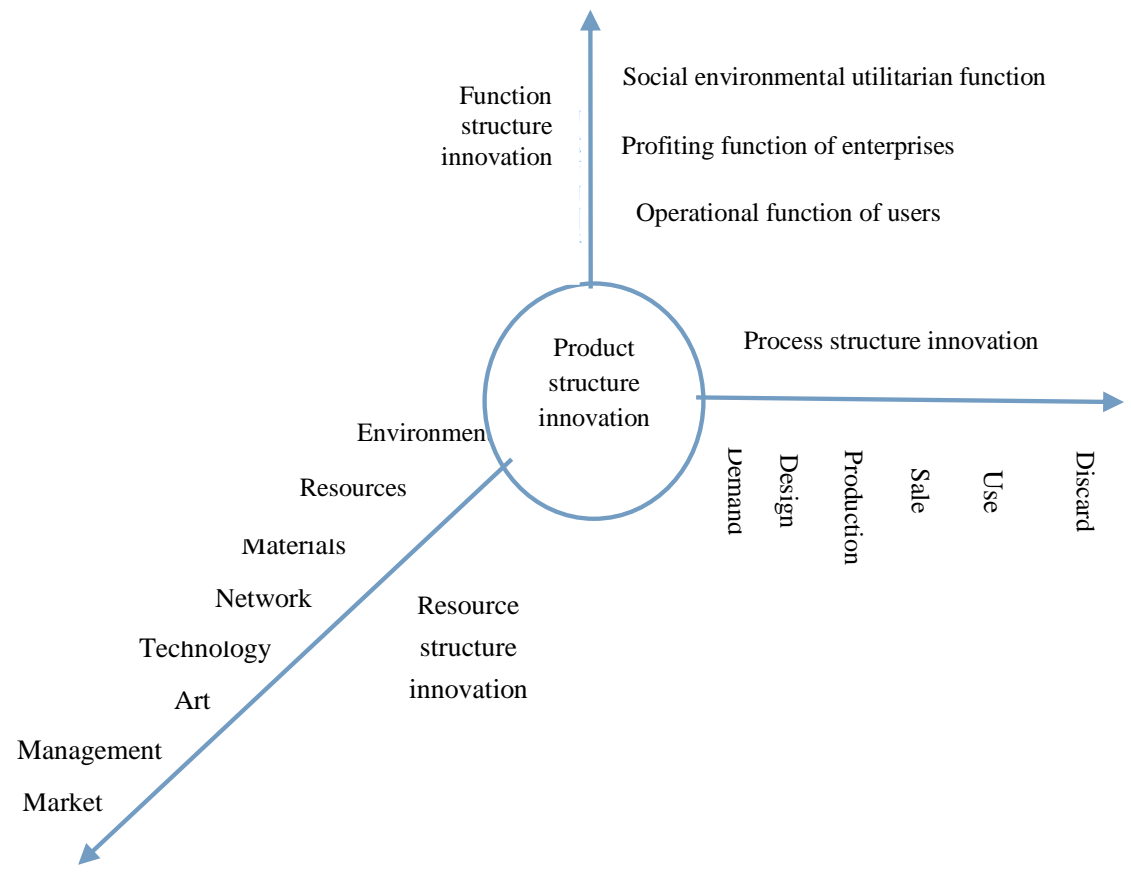

Fig. 2. Three-Dimensional Model of Analysis of Structure Innovation.

\section{B. Innovation and Cost}

1) Cost analysis of the product innovation: Through analysis from the concept of the value engineering, the expression of the cost can be expressed as $\mathrm{C}=\mathrm{F} / \mathrm{V}$ (where: $\mathrm{V}$ Value; F-Function; C-Cost) which shows that the cost is a relative value. The lowest cost required by the value engineering refers to the relative value of the cost rather than the absolute value of the cost. The maximum value product innovation pursues the optimization of the function when the absolute capital expense of products will greatly increase. In other words, the capital expense cannot simply reflect on the cost of products. The innovation cost of products is equal to the comprehensive cost of the internal cost and the external cost. The internal cost refers to labor cost, material cost, consumption cost, management cost and other costs produced in the process of design, production and sale. The external cost mainly includes environmental pollution cost, risk cost (the risk cost comes from the technical complexity and limitations of the technical risk recognition and predictability of the technological innovation subject), using cost, health cost, resource cost and other social costs. The cost calculation of product innovation is an extremely complex engineering, which depends on complexity of function evaluation, value evaluation and external cost. At present, most of cost calculations in the realistic society only calculate the internal cost and do not or seldom calculate the external cost, which is the major social problem existed in the cost calculation of products. For example, provided the social cost fails to or fails to fully reflect on the consumption cost of consumers, it will not affect utilitarian value judgment of consumers about innovation products. Therefore, they usually consume more this kind of innovative products. Considering the innovator does not need to or fully need to bear the social cost or owing to asymmetry of foreseen information of technical risks, it is difficult to determine the social cost of the innovator. Therefore, it does not affect the profiting level of the innovator through the innovation behavior. The behavior of the innovator is to produce more innovative products [11].Therefore, the comprehensive cost of the internal cost and the external cost of the product innovation should be fed back to the product price, affect the consumption behavior and make the innovation cost evaluation more objective, systematical and scientific.

2) Reduction of cost through innovation: Enterprises can reduce cost through the mechanism innovation. Enterprises can establish the comprehensive cost feedback mechanism, consider the comprehensive cost evaluation of the product innovation in production, use, consumption, environment, discard behavior as the basic requirements of the design of the technical innovation mechanism, feed the evaluation cost to the price of goods, use market means to weed out the high cost innovation, realize the comprehensive cost control of innovation. Enterprises can seek the external innovation resources through collaborative innovation, adopt various ways to carry on exchange and cooperation with the external subject, obtain innovation resources, shorten innovation cycle, and lower innovation risks [12]. The cost can be reduced through technological innovation. Enterprises can realize the technology integration and diversified functions of products through technical integrated innovation, enhance the use efficiency of products, improve the product procedure or service and remove technology, knowledge and skills that make no contribution to demands and requirements of users 
so as to effectively reduce the cost. Through technological innovation, the social cost of products can be reduced. Costs of such real cases as 3D printing technology, new energy automobiles and solar energy products are reduced through innovation. Through technological innovation, many industrial products become more miniaturized, microscopic, terminalized and virtualized, reduce material consumption, energy consumption and operating cost and realize reduction of the cost. For example, design of Apple ipad. For another example, the product terminal based on the internet of things will realize the full-time remote control and reduce the operating cost of products.

\section{Innovation and Value}

The product design innovation is the organic unity of technological value, artistic value, social and economic value, natural ecological value and human-oriented value [13]. It is the innovation and optimization of the product value and the system innovation and optimization of function, structure and cost of the value system. It is the value innovation process in which the minimum comprehensive cost, the highest comprehensive function and the maximum value can be realized through enhancement of the product function and reduction of the product cost [14]. The innovation refers to reorganize the value structure, change the original value chain, make the original value chain osculate and change [15] and form the action results of the new product value structure. In the real market environment, the value of the product design innovation needs concrete evaluation (as shown in the "Fig. 3", the legend of which is made by the author), finally gain the reliable criterion of the innovation value through scientific evaluation and realize the maximum value of the product innovation.

$$
V=\frac{F_{1}+F_{2}+F_{3}}{C_{1}+C_{2}}
$$

Fig. 3. Mathematical Model of the Design Innovation Value

( $V$ refers to the maximum value; $F_{1}$ refers to the using function of users, $F_{2}$ refers to the profiting function of enterprises, and $F_{3}$ refers to the environmental utilitarian function; $C_{1}$ refers to the internal cost, and $C_{2}$ refers to the external cost;)

\section{CONCLUSION}

Through the study, this paper comes to the following conclusions: Under the concept of the value engineering, the product design innovation includes the overall innovation of value, function and cost evaluation throughout the whole life of products. Through the function innovation, the product function can be perfected and enhanced; through the cost evaluation innovation, the cost evaluation can become more comprehensive, systematic and scientific and the reduction of the cost can be realized through innovation. The final achievement of the value innovation is to realize the maximum social value of the product innovation. The reliable criterion of the maximum social value is the system calculation evaluation on the operational function, benefit function, environmental utilitarian function of the product innovation and the comprehensive cost of product innovation.

\section{REFERENCES}

[1] Li Keqiang. The State Council of the CPC Central Committee held the National Science and Technology Awards Conference Ceremoniously [N]. People's Daily, 2014-1-11 (01).

[2] Wang Naijing. An Introduction to the Value Engineering [M]. Beijing: Economic Science Publishing House, 2006.

[3] Wang Lina, Yuan Yongbo. Study on the Green Building Investment Decision Based on the Value Engineering [J]. Value Engineering, 2011(01): 26-27

[4] Wang Fei. Realization of the Maximum Value of the Whole Society is the Highest Goal of the Value Engineering [J]. Value Engineering, 2011(01): 28-30.

[5] Xu Zhilei. Science on the Innovation Design [C]. Shenyang: Collected Papers of the 2013 China International Industrial Design Forum, 2013: $1-5$.

[6] Pi Yongsheng. Application of the Functional Analysis in the Product Design [J], Packaging Engineering, 2012, 33(18): 136-139.

[7] Chang Shaoshun. A Brief Discussion on the System Innovation [J]. Chinese Journal of Systems Science, 2012, 20(2): 1-4.

[8] Zhu Konglai, Le Feifei. Reflection on Theoretical and Practical Issues Related to the Integrated Innovation [J].Economic Review, 2011(10) 31-34.

[9] Chen Xiangdong, Yan Hong, Liu Ying. Integrated Innovation and Module Innovation--Strategic Complementation of Innovation Activities [J]. China Soft Science, 2002(12): 52-56.

[10] Li Jinhai, Cui Jie, Liu Lei. Study on the Conceptual Structure Mode Based on the Corporative Innovation [J], Journal of Hebei University of Technology, 2013, 42(1):112-118.

[11] Li Guangpei. Exploration on the Social Cost of the Technological Innovation [J].Studies in Science of Science, 2013, 31(4): 605-610.

[12] Huang Sujian, Wang Xin, Ye Shuguang, et al. Study on the Open System Innovation Mode [J]. China Industrial Economics, 2010(2): 130-139.

[13] Li Guangpei. Exploration on the Calculation Index System of the Social Cost of the Technological Innovation [J]. Technology Economics, 2012, 31(10): 13-18.

[14] Chen Hongjuan, Peng Xingchen. Study on the Application of the Value Engineering in the Product Innovation Design [J].Packaging Engineering, 2011, 32(8): 62-64.

[15] Fang Xin, Yu Jiang. Systematic Technological Innovation and Reconstruction of the Value Chain [J]. Journal of Quantitative \& Technical Economics, 2002 (7): 5-8. 